\title{
Knowledge Sharing in Virtual Distributed Environments: Main Motivators, Discrepancies of Findings and Suggestions for Future Research
}

\author{
Yongsi Chen and Khe Foon Hew
}

\begin{abstract}
Knowledge sharing research has proposed various theories and explanations regarding individuals' intentions to share knowledge in virtual distributed communities. Although past research studies can provide useful insights into the factors that significantly affect knowledge sharing intention, there are some discrepancies of findings among the different studies. The main purpose of this paper is to review the previous empirical research studies to first identify the main theories and factors used to explain online knowledge sharing. The findings suggest that these incentive items could be grouped into three main categories: personal factors (knowledge self-efficacy, perceived relative advantage, perceived compatibility), social factors (trust, reciprocity, social network ties), and organizational factors (formal incentive mechanism). Of these factors, trust has been the most widely discussed, followed by social network ties. Next, this paper presents several main discrepancies among past research studies in order such as the notion of perceived compatibility, norm of reciprocity, and trust to provide possible directions for future studies.
\end{abstract}

Index Terms-Knowledge sharing, virtual community of practice, motivation, finding discrepancies.

\section{INTRODUCTION}

Knowledge is believed to be the most valuable resource for organizations to develop organizational growth and maintain their advantages [1]-[3] in a competitive and dynamic economy [4]. Because knowledge is seen as a critical resource, many organizations have invested money and effort in knowledge management initiatives. Knowledge management may be defined as a complex socio-technical system that encompasses various forms of knowledge generation, storage, representation, and sharing [5]. During the last decade, the notion of knowledge management (KM) has increasingly been adopted by many organizations and institutes of higher learning. Of these various forms, knowledge sharing has been identified as a major issue for any knowledge management initiative [6], [7].

Also, the rapid development of Internet has led to a proliferation of virtual communities [8]-[10]. The emergence of virtual communities is recognized as one possible solution to knowledge management and sharing in organizations [11]. Enabling virtual communities with the use of online interactive technologies is also believed to be a strategy for knowledge management [12]. Indeed, several scholars have

Manuscript received March 30, 2014; revised May 30, 2014.

The authors are with the Division of Information \& Technology Studies, Faulty of Education at the University of Hong Kong, Pokfulam Road, Hong Kong (e-mail: vincychan928@gmail.com, kfhew@hku.hk). suggested that in today's multinational and geographically dispersed organizations or institutions, online environments are potentially much more viable facilitators of knowledge sharing than traditional face-to-face environments.

Because of the potential benefits that can be achieved through virtual communities, an increasing number of studies have been conducted to investigate individual-level knowledge sharing behavior in virtual communities. For instance, researchers have been investigating what factors motivate successful knowledge sharing [1], [9], [11], [13]-[21] and what factors hinder knowledge sharing among individuals [1], [11], [12], [17]. Although these studies provide useful insights into the factors that significantly affect the behavior of knowledge sharing, there are some discrepancies of findings among the different studies. For example, a number of studies indicated trust as a positive factor that motivates knowledge sharing intention [20], which results in the contribution to the actual knowledge sharing behavior. However, there are some other studies suggesting that the influence of trust in knowledge sharing behavior is not significant [14].

The purpose of this paper is to review the previous empirical research studies to first identify the main theories and factors used to explain online knowledge sharing. We found that the main theories used to explain the phenomenon of knowledge sharing include social exchange theory, social capital theory, social cognitive theory, and behavioral theories (e.g., theory of reasoned action, theory of planned behavior, and technology acceptance model). Further analysis of the studies reveals that the specific factors that motivate knowledge sharing could be grouped into three main categories: personal factors (knowledge self-efficacy, perceived relative advantage, perceived compatibility), social factors (trust, reciprocity, social network ties), and organizational factors (formal incentive mechanism). We also present several main discrepancies among past research studies in order to provide possible directions for future studies.

The remainder of this article is organized as follows. Section II introduces the main concepts of knowledge, knowledge sharing, and virtual community. The related theories and theoretical foundations related to knowledge sharing are presented in Section III. Section IV focuses on the specific factors that influence knowledge sharing among individuals. By comparing the findings of different studies, we present the observed discrepancies in Section V. Finally, implications and conclusions for possible directions of further work are discussed in Section VI. 


\section{DEFINITION}

\section{A. Knowledge and Knowledge Sharing}

Knowledge has long been recognized as the most valuable resource to sustain competitive advantage for organizations [4]. This belief is widely adopted in other studies, such as [1] and [22]. But what is this critical resource called knowledge? Various scholars have attempted to define knowledge and how it might be differentiated from information [4]. In this paper, we believe that there is little practical utility in trying to make a distinction. We consider knowledge as information possessed in the mind of individuals related to procedures, facts, concepts, ideas and judgments that can help an individual take action (e.g., solve work-related problems, use a machine, write a research paper) [23], [24].

According to Hendriks [6], knowledge sharing happens when there is communication between two parties: knowledge owners and knowledge reconstructions. The process of knowledge sharing typically begins when an individual, identified as a knowledge reconstructor, begins a conversation by posting a question or requests for help on a certain information technology platform such as a discussion forum, wiki, or email listserv. In response, an individual known as knowledge owner, presuming that he or she is willing to help, may externalize and share his or her knowledge in the form of a document, diagram, or narrative describing a similar experience where a method or technique was used to solve a problem, or contact information on someone else who might know. Knowledge sharing therefore presumes an act of externalization by the knowledge owners [6]. The knowledge reconstructors, on the other hand, should be able to perceive these expressions of knowledge and make sense of them [6].

Essentially, the purpose of knowledge sharing is to improve the competitive advantage of organizations and individuals' action capability [25] through knowledge contribution and knowledge seeking for reuse [11]. Several previous research studies have addressed two main types of knowledge to be shared as tacit knowledge, which is implicit, semiconscious and unconscious knowledge within individuals' head [26] and explicit knowledge, which is expressed through certain formats [27]. Another study divides knowledge from a practical point of view as book knowledge, practical knowledge and cultural knowledge [28]. Book knowledge refers to the policies or standards pertaining to a particular subject discipline, while practical knowledge refers to the application of book knowledge in practice (e.g., how to use certain design standards in Web development). Cultural knowledge refers to the cultural meanings and beliefs about how professionals should approach their work and develop professional identities [29].

\section{B. Virtual Community}

Virtual communities are the informal entities, existing in computer-mediated environments that share the same interests, goals or practices. These entities interact to share knowledge [1], [9], [29]. The notion of virtual community is gathering popularity in formal and informal learning [30], [31].

\section{MAIN RELATED THEORY}

\section{A. Social Exchange Theory}

The social exchange theory (SET) was first proposed by Homans [32] and has been adopted in other studies [33]. The social exchange theory is derived from the economic exchange theory (EXT), but differs from EXT as it includes many social factors, such as status, respect and approval [33], which are not apparent in EXT [34]. Based on SET, knowledge is believed to be a commercial good that can be exchanged through the knowledge market [34].

There are two main factors that facilitate knowledge exchange activities: a) tangible returns, such as organizational rewards, perceived competitive advantage and access to information and knowledge, and b) intangible returns, such as perceived reputation. Thus individuals' motivations to share knowledge can be classified into extrinsic and intrinsic motivations. Extrinsic motivation refers to individuals gaining tangible reward or valuable outcome in return for the knowledge sharing contribution [35]. Intrinsic motivation, on other hand, refers to individuals being driven by intangible reward such as satisfaction and enjoyment gained from the process of knowledge sharing activities [35].

\section{B. Social Capital Theory and Social Cognitive Theory}

Social capital refers to the benefits derived from relationships among individuals that can lead to certain rewards or to facilitate certain types of actions [36]. Social capital can be divided into private goods social capital and public goods social capital. Private goods social capital may be viewed as networks that generate social capital for individuals [37], which can foster direct benefits for individuals. Also, Leana and Van Buren [37] suggested that social networks are valued highly among social capital, which indicates social capital as public goods. From the perspective of knowledge sharing, social capital can be grouped into three distinct dimensions, including a) structural dimension, such as social network ties, b) relational dimension, such as norm of reciprocity, trust and identification, and (c) cognitive dimension, such as shared language and share vision [1], [38].

Social cognitive theory has been widely adopted as the theoretical model in knowledge sharing research. Social cognitive theory defines human behavior as a triadic, dynamic and reciprocal interaction among cognitive, behavioral, and environmental factors [39]. According to social cognitive theory, self-efficacy factor, referring to the individuals' confidence to achieve specific types of performance [40], is one of the most significant motivators that can affect human behavior.

\section{Behavioral Theories}

Behavioral theories indicate that knowledge sharing behavioral is positively affected by knowledge sharing intention [41]. Theory of reasoned action, theory of planned behavior and technology acceptance model are the most widely used behavioral theories among knowledge sharing research studies.

According to the theory of reasoned action, knowledge sharing intention is affected by individuals' attitude toward a behavior and subjective norms [42]. In other words, the theory of reasoned action indicates that if people evaluate knowledge sharing behavior as something positive (attitude), and if they perceive other significant people want them to 
share knowledge (subjective norm), this would result in a higher motivation to share knowledge and they are more likely to do so.

Extending from the theory of reasoned action, the theory of planned behavior, proposed by Ajzen and Fishbein [42], includes the notion of perceived behavioral control, which refers to people's perceptions of their ability to perform a particular behavior. Perceived behavior control is usually determined by certain control beliefs, which refers to the beliefs about the presence of factors that may facilitate or impede performance of the behavior. In the context of knowledge sharing, two specific control beliefs - knowledge self-efficacy and web-specific self-efficacy can determine an individual's perceived ease or difficulty in sharing knowledge.

Technology acceptance model is first proposed by Davis, Bagozzi and Warshaw [43], focusing on individuals' attitude toward information technology. This theory contains two variables as perceived usefulness and perceived ease of use. Perceived usefulness refers to individuals' willingness to use new technology to improve their job performance, while perceived ease of use refers to individuals' confidence to use new technology. In other words, perceived usefulness answer is "the degree to which a person believes that using a particular system would enhance his or her job performance 'and perceived ease of use is "the degree to which a person believes that using a particular system would be free of effort [43].

\section{POSSIBLE FACTORS}

In this section, the present review will identify the most widely discussed specific motivation factors that can influence knowledge sharing in virtual distributed communities. These factors can be grouped into three categories: personal factors (knowledge self-efficacy, perceived relative advantage, perceived compatibility), social factors (trust, reciprocity, social network ties), and organizational factors (formal incentive mechanism).

\section{A. Personal Factors}

\section{1) Knowledge sharing self-efficacy}

According to social cognitive theory, self-efficacy is assumed to be a significant motivator of individuals' knowledge sharing intention. Self-efficacy is defined as individuals' confidence in providing knowledge that is valuable for sharing [44]. Many researchers indicated that self-efficacy plays as a vital role in facilitating knowledge sharing intention. Thus, individuals who have higher self-efficacy are supposed to be more comfortable and willing to share knowledge. This belief is supported by some research studies [11], [20], [21]. Specifically, Chen and Chen [21] reported that knowledge sharing self-efficacy is positively related to the knowledge contributing and knowledge collecting behavior of members among virtual community of practice.

\section{2) Perceived relative advantage}

Perceived relative advantage refers to the notion that an individual's willingness to share knowledge is determined by the perceived expected benefits that can be reaped [45], such as increased job performance, economic benefits and enhanced expertise [46]. In other word, individuals are more likely to share knowledge when they have strong perceived relative advantage of knowledge sharing. For example, individuals in virtual communities of practice are more willing to share knowledge if they believe that "sharing knowledge will increase my solving-problem capability or it will help me in my job and improve my performance" [20]. Perceived relative advantage is assumed to be a positive motivator for knowledge sharing intention and behavior [11], [20].

\section{3) Perceived compatibility}

Perceived compatibility is derived from the Innovation Diffusion Theory [46], referring to the likely belief, value and experience of knowledge contributors [20]. In other words, perceived compatibility is consistency of existing value system of individuals. Researchers assumed that knowledge is easily to be shared among individuals if the new concept is consistent with the existing value system, which indicates that perceived compatibility has positive impact on knowledge sharing behavior [11], [20], [47].

\section{B. Social Factors}

\section{1) Trust}

Trust is defined as individuals' belief in good intention to perform knowledge-sharing behavior with respect to the community [14], [20], [48], [49]. There are three dimensions of trust as ability-based (capability to manage the virtual community of practice) trust [13], [50], integrity-based (not taking advantage from others) trust [9], [50] and benevolence-based (concerns for the needs of others) trust [13]. Trust is assumed to be a significant motivator to increase individuals' willingness to share knowledge and most of the studies of knowledge sharing have proposed assumptions based on the effectiveness of trust in knowledge sharing [10], [11], [13], [15], [47].

\section{2) Reciprocity}

Reciprocity is based on the social exchange theory, which refers to the expectation that knowledge receiver should return the favor to the knowledge giver. Lin, Hung and Chen [20] indicated knowledge exchanges are mutual and driven by obligation and fair. This belief is also consistent with the concept of reciprocity from studies of Wasko and Faraj [1], Hung and Cheng [47] and Chen and Hung [11]. Reciprocity can be further classified as direct reciprocity, which involves two individuals take the roles as receiver and giver of knowledge exchange [51], and generalized reciprocity, which occurs when individuals share knowledge in return to other members of the virtual community of practice other than the original knowledge giver.

\section{3) Social network ties}

Social network ties refer to the channels for information and resource flows [52]. In other words, the concept of social network ties posits that knowledge sharing happens when individuals interact with each other such as by posting and responding to online messages in a virtual distributed environment [1]. Based on the social capital theory, social network ties is one of the significant structure motivations for knowledge sharing [1], [38]; individuals who are connected to a large number of other people are more likely to sustain their sharing of knowledge [1]. 


\section{Organizational Factors}

\section{1) Incentive mechanism}

Successful incentive mechanism is supposed to be a motivation for knowledge sharing [12]. For example, virtual coin system and virtual badge system are embedded in many virtual communities to reward users with better reputation in return for their contribution to the communities. Chen, Chang and Liu [29] conducted an empirical experiment based on the assumption that successful incentive mechanism is positively correlated to knowledge sharing behavior and individuals' satisfaction of sharing knowledge in virtual community of practice. Well-designed incentive mechanism has positive impact on knowledge sharing. If a member's effort of sharing knowledge is credited and results in expected rewards, he or she will be more likely to continue sharing knowledge. In these ways, incentive mechanism has direct influence toward knowledge sharing intention. Also, if the environment of virtual community of practice is respectful and fair (facilitating condition), individuals are likely to share knowledge for personal satisfaction.

The following clustered bar chart (Fig. 1) presents all the possible factors, which have been discussed among twenty-nine prior studies. Of these factors, trust has been the most widely discussed, followed by social network ties.

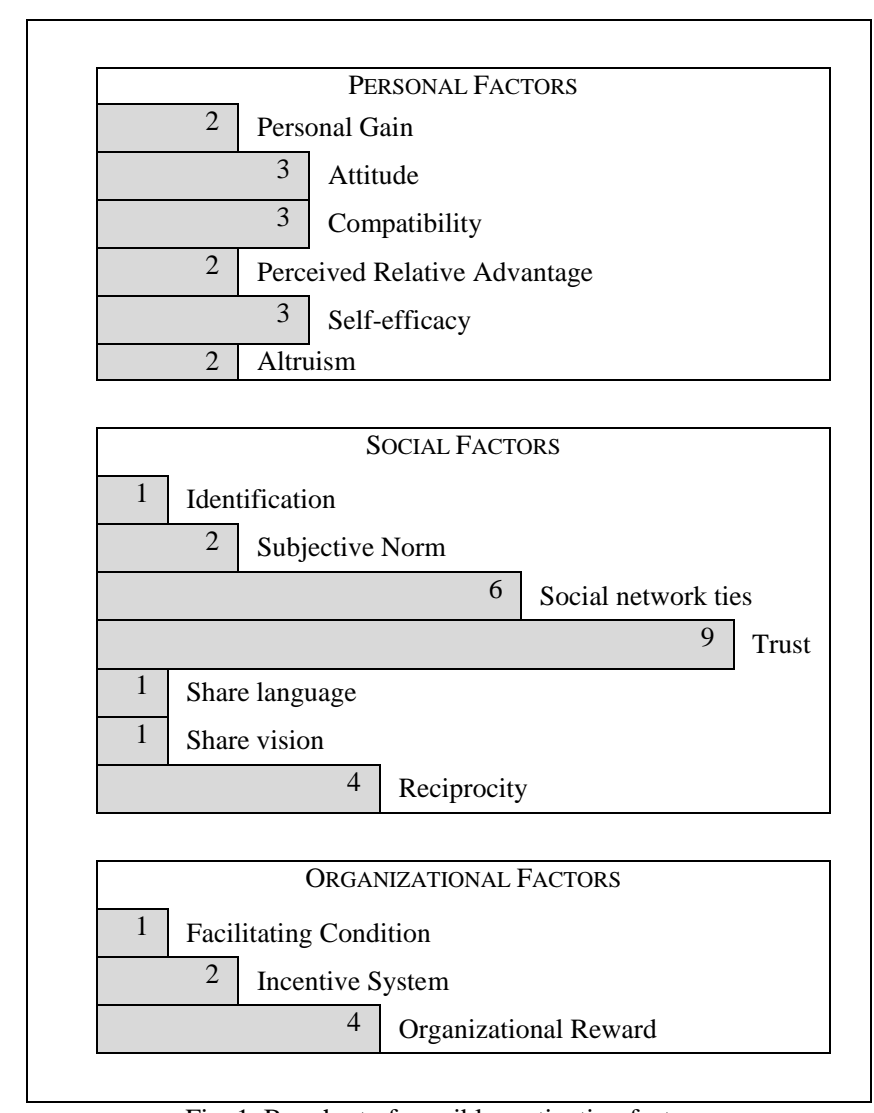

Fig. 1. Bar chart of possible motivation factors.

\section{FINDINGS DISCREPANCIES AND EXPLANATION}

Table I shows some of the discrepancies found in the reviewed previous studies. Both of the findings in the studies of Chen and Hung [11] and Lin et al. [20] clearly support the assumption that perceived compatibility positively affect individuals' knowledge sharing behavior. Compatibility is proved to be an important predictor to motivate knowledge-sharing intention [20], which indicates that users are more willing to share related information with other members of virtual communities if an innovation is perceived as being compatible with users' existing values [11], such as lifestyle, work attitude, and concepts in knowledge sharing. However, while referring to a more specific concept as compatibility of technology use, the experiment results from the study of Hung and Cheng [47] rejected the positive impact that the compatibility of technology use has on knowledge sharing intention. One possible explanation is the specific kind of compatibility (e.g., compatibility of technology use) might not inherit the effectiveness from generalized compatibility. Generalized compatibility refers to users' knowledge sharing behavior that is in accordance with their original value system, a coherent set of established values, habits or norms producing certain behaviors and involving in the decision making of individuals. Technology-specific compatibility emphases on users' previous experience of technology use, which focuses on users' capability on using technology in knowledge sharing activity. However, the effectiveness of technology-specific compatibility is independent of generalized compatibility. In other words, the previous experience of using technology is more like a barrier than a motivator in knowledge sharing activity. Individuals' satisfaction and willingness to contribute knowledge decrease dramatically if they cannot finish the task with the technology they are using [47].

Another finding discrepancy lies in the concept of reciprocity. Most of the studies assumed reciprocity as a motivator but empirical studies have proved it to be an insignificant factor to knowledge sharing intention. From the result of an empirical experiment (350 valid empirical data was collected from three PVCs) of the study of Lin, Hung and Chen [20], there is no direct correlation between knowledge sharing behavior with reciprocity. However, the correlation between reciprocity with trust is supported [20], which indicates an indirect positive impact that reciprocity has on knowledge sharing intention. Also, finding from the study of Chen and Hung [11] rejected the assumption of reciprocity as a positive affect to members' knowledge sharing behavior in PVCs (323 valid empirical data was collected from two virtual IT-related sites). However, the qualitative case study from Hew and Hara [14] through online observation and interviews found that reciprocity is the most common single motivator that motivates knowledge sharing behavior among three PVCs (Advanced Nursing Practice, University Web Development and Literacy Education). Thirty out of Bartol and Srivastava [24] participants indicated that they are intended to share knowledge because of a sense of responsibility. The finding discrepancy may come from the different methodology designs as the first two studies are designed empirical experiment while the data from Hew and Hara [17] is conducted from observation and interviews. Future research studies should draw attention to investigate the motivational effects of reciprocity, especially the generalized reciprocity, on knowledge sharing behavior.

Some of the research studies believe trust as a motivator to knowledge sharing behavior [11], [13], [15], [20]. The results of findings from these studies support the positive correlation between trust and knowledge sharing behavior. According to Blau [33], trust creates and fosters exchange relationships, 
which may result in leading sharing knowledge of good quality. However, other studies [9], [14] rejected the assumption of motivational impact of trust. Specifically, the type of trust examined in the two studies [9], [14] was integrity-based trust which refers to the belief that people in the community would refrain from taking advantage of each other (opportunistic behavior). One possible explanation is that the two communities being examined were based on less risky knowledge sharing relationships such as among individuals who hardly interact or have close working relationships. In less risky relationships it may be reasonable to expect that the need for integrity-based trust to be minimal.

TABLE I: FINDINGS DISCREPANCIES

\begin{tabular}{|c|c|c|c|}
\hline Factor & Source & Assumption & Finding \\
\hline \multirow{3}{*}{$\begin{array}{l}\text { Perceived } \\
\text { compatibility }\end{array}$} & Lin et al., 2009 & $\begin{array}{l}\text { Members' perceived } \\
\text { compatibility positively } \\
\text { affects their knowledge } \\
\text { sharing behavior in } \\
\text { PVCs. }\end{array}$ & Significant \\
\hline & $\begin{array}{l}\text { Chen and Hung, } \\
2010\end{array}$ & $\begin{array}{l}\text { Perceived compatibility } \\
\text { is positively related to } \\
\text { the knowledge } \\
\text { contributing behavior of } \\
\text { members in PVCs. } \\
\text { Perceived compatibility } \\
\text { is positively related to } \\
\text { the knowledge } \\
\text { collecting behavior of } \\
\text { members in PVCs. }\end{array}$ & Significant \\
\hline & $\begin{array}{l}\text { Hung and } \\
\text { Cheng, } 2013\end{array}$ & $\begin{array}{l}\text { The level of } \\
\text { compatibility of the } \\
\text { community users with } \\
\text { technology has a } \\
\text { positive effect on their } \\
\text { intentions to engage in } \\
\text { knowledge- sharing. }\end{array}$ & $\begin{array}{l}\text { Not } \\
\text { significant }\end{array}$ \\
\hline \multirow{6}{*}{$\begin{array}{l}\text { Norm of } \\
\text { Reciprocity }\end{array}$} & Lin et al., 2009 & $\begin{array}{l}\text { The norm of reciprocity } \\
\text { positively affects } \\
\text { members' knowledge } \\
\text { sharing behavior in } \\
\text { PVCs. }\end{array}$ & $\begin{array}{l}\text { Not } \\
\text { significant }\end{array}$ \\
\hline & $\begin{array}{l}\text { Chen and Hung, } \\
2010\end{array}$ & $\begin{array}{l}\text { The norm of reciprocity } \\
\text { is positively related to } \\
\text { the knowledge } \\
\text { contributing behavior of } \\
\text { members in PVCs. }\end{array}$ & $\begin{array}{l}\text { Not } \\
\text { significant }\end{array}$ \\
\hline & $\begin{array}{l}\text { Wasko and } \\
\text { Faraj, } 2005\end{array}$ & $\begin{array}{l}\text { Generalized reciprocity } \\
\text { is positively related to } \\
\text { the knowledge sharing } \\
\text { behavior of members in } \\
\text { PVCs. }\end{array}$ & $\begin{array}{l}\text { Not } \\
\text { significant }\end{array}$ \\
\hline & \multirow[b]{2}{*}{ Chiu et al., 2006} & $\begin{array}{l}\text { Norm of reciprocity is } \\
\text { positively associated } \\
\text { with the quantity of } \\
\text { knowledge sharing. }\end{array}$ & Significant \\
\hline & & $\begin{array}{l}\text { Norm of reciprocity is } \\
\text { positively associated } \\
\text { with the quality of } \\
\text { knowledge shared by } \\
\text { members. }\end{array}$ & $\begin{array}{l}\text { Not } \\
\text { significant }\end{array}$ \\
\hline & $\begin{array}{l}\text { Hew and Hara, } \\
2007\end{array}$ & $\begin{array}{l}\text { Reciprocity is a } \\
\text { motivator to knowledge } \\
\text { sharing. }\end{array}$ & Significant \\
\hline \multirow{3}{*}{ Trust } & Lin et al., 2009 & $\begin{array}{l}\text { Trust positively affects } \\
\text { members' knowledge } \\
\text { sharing behavior in } \\
\text { PVCs. }\end{array}$ & Significant \\
\hline & $\begin{array}{l}\text { Wang and Wei, } \\
2011\end{array}$ & $\begin{array}{l}\text { Community trust has a } \\
\text { positive effect on the } \\
\text { knowledge sharing } \\
\text { intentions of virtual } \\
\text { community members. }\end{array}$ & $\begin{array}{l}\text { Not } \\
\text { significant }\end{array}$ \\
\hline & Liu and Li, 2012 & $\begin{array}{l}\text { Trust is possibility } \\
\text { related to knowledge } \\
\text { sharing. }\end{array}$ & Significant \\
\hline
\end{tabular}

\begin{tabular}{l|l|l}
\hline \multirow{2}{*}{$\begin{array}{l}\text { Chen and Hung, } \\
2010\end{array}$} & $\begin{array}{l}\text { Interpersonal trust is } \\
\text { positively related to the } \\
\text { knowledge contributing } \\
\text { behavior of members in } \\
\text { PVCs. } \\
\text { Interpersonal trust is } \\
\text { positively related to the } \\
\text { knowledge collecting } \\
\text { behavior of members in } \\
\text { PVCs. }\end{array}$ & \multirow{2}{*}{ Significant } \\
\hline \multirow{2}{*}{ Shu and } & $\begin{array}{l}\text { Does the level of trust in } \\
\text { virtual communities } \\
\text { influence the attitude of } \\
\text { users toward knowledge } \\
\text { sharing in virtual } \\
\text { communities? }\end{array}$ & Significant \\
& $\begin{array}{l}\text { Trust is positively } \\
\text { associated with the } \\
\text { quantity of knowledge } \\
\text { sharing. }\end{array}$ & $\begin{array}{l}\text { Not } \\
\text { significant }\end{array}$ \\
\hline \hline
\end{tabular}

\section{CONCLUSION}

This present paper reviewed the previous research studies and highlights the main related theories (Section III), and the most commonly mentioned factors of knowledge sharing intention (Section IV). This review also highlights the major observed discrepancies: perceived compatibility, reciprocity and trust, with possible directions for future studies are also provided for each concept respectively. In addition, we found that a majority of research studies to date tend to examine knowledge sharing on the part of the sharers or providers. The question of whether the receivers are actually able to perceive these expressions of knowledge, and make sense of them to improve individual or team performance is largely left unanswered. We also notice that a majority of research studies merely investigate an individual's self-perceived intention to share knowledge. More research is needed to determine if mere intention will actually translate to actual knowledge sharing activity. Finally, research on possible factors that could sustain online knowledge sharing over a prolong time period is rare. Future studies should examine factors that could sustain longitudinal knowledge sharing behavior.

\section{REFERENCES}

[1] M. M. Wasko and S. Faraj, "Why should I share? Examining social capital and knowledge contribution in electronic networks of practice," MIS quarterly, pp. 35-57, 2005.

[2] G. Casimir, Y. N. K. Ng, and C. L. P. Cheng, "Using IT to share knowledge and the TRA," Journal of Knowledge Management, vol. 16, no. 3, pp. 461-479, 2012

[3] S. Fernie, S. D. Green, S. J. Weller, and R. Newcombe, "Knowledge sharing: context, confusion and controversy," International Journal of Project Management, vol. 21, no. 3, pp. 177-187, 2003.

[4] T. H. Davenport and L. Prusak, Working knowledge: Managing what your organization knows, Boston, MA: Harvard Business School Press, 1998.

[5] A. Ardichvili, M. Maurer, W. Li, T. Wentling, and R. Stuedemann, "Cultural influences on knowledge sharing through online communities of practice," Journal of Knowledge Management, vol. 10 , no. 1, pp. 94-107, 2006.

[6] P. Hendriks, "Why share knowledge? The influence of ICT on the motivation for knowledge sharing," Knowledge and process management, vol. 6, no. 2, pp. 91-100, 1999.

[7] M. M. Wasko and S. Faraj, "It is what one does: Why people participate and help others in electronic communities of practice," Journal of Strategic Information Systems, vol. 9, pp. 155-173, 2000.

[8] S. R. Hiltz and B. Wellman, "Asynchronous learning networks as a virtual classroom," Communications of the ACM, vol. 40, no. 9, pp. 44-49, 1997. 
[9] C. M. Chiu, M. H. Hsu, and E. T. Wang, "Understanding knowledge sharing in virtual communities: An integration of social capital and social cognitive theories," Decision support systems, vol. 42, no. 3, pp. 1872-1888, 2006.

[10] Y. H. Fang and C. M. Chiu, "In justice we trust: Exploring knowledge-sharing continuance intentions in virtual communities of practice," Computers in Human Behavior, vol. 26, no. 2, pp. 235-246, 2010.

[11] C. J. Chen and S. W. Hung, "To give or to receive? Factors influencing members' knowledge sharing and community promotion in professional virtual communities," Information \& Management, vol. 47, no. 4, pp. 226-236, 2010

[12] A. Ardichvili, V. Page, and T. Wentling, "Motivation and barriers to participation in virtual knowledge-sharing communities of practice," Journal of knowledge management, vol. 7, no. 1, pp. 64-77, 2003.

[13] W. Shu and Y. H. Chuang, "Why people share knowledge in virtual communities," Social Behavior and Personality: an international journal, vol. 39, no. 5, pp. 671-690, 2011

[14] W. T. Wang and Z. H. Wei, "Knowledge sharing in wiki communities: an empirical study," Online Information Review, vol. 35, no.5, pp. 799-820, 2011.

[15] Y. C. Liu and F. C. Li, "Exploration of Social Capital and Knowledge Sharing," International Journal of Distance Education Technology vol. 10, no. 2, pp. 17-38, 2012.

[16] H. L.Yang and C. Y. Lai, "Motivations of Wikipedia content contributors," Computers in Human Behavior, vol. 26, no.6, pp. 1377-1383, 2010.

[17] K. F. Hew and N. Hara, "Knowledge sharing in online environments: A qualitative case study," Journal of the American Society for Information Science and Technology, vol. 58, no. 14, pp. 2310-2324, 2007.

[18] S. Y. Hung, H. M. Lai, and W. W. Chang, "Knowledge-sharing motivations affecting R\&D employees' acceptance of electronic knowledge repository," Behaviour \& Information Technology, vol. 30, no. 2, pp. 213-230, 2011.

[19] S. C. Ho, P. H. Ting, D. Y. Bau, and C. C. Wei, "Knowledge-Sharing intention in a virtual community: a study of participants in the Chinese Wikipedia," Cyberpsychology, Behavior, and Social Networking, vol.14, no. 9, pp. 541-545, 2011.

[20] M. J. J. Lin, S. W. Hung, and C. J. Chen, "Fostering the determinants of knowledge sharing in professional virtual communities," Computers in Human Behavior, vol. 25, no. 4, pp. 929-939, 2009.

[21] I. Y. Chen and N. S. Chen, "Examining the Factors Influencing Participants' Knowledge Sharing Behavior in Virtual Learning Communities," Journal of Educational Technology \& Society, vol. 12, no. 1, 2009.

[22] N. J. Foss and T. Pedersen, "Transferring knowledge in MNCs: The role of sources of subsidiary knowledge and organizational context," Journal of International Management, vol. 8, no. 1, pp. 49-67, 2002.

[23] M. Alavi and D. E. Leidner, "Knowledge Management and knowledge management systems: Conceptual foundations and research issues," MIS Quarterly, vol. 25, no. 1, pp. 107-136, 2001.

[24] K. M. Bartol and A. Srivastava, "Encouraging knowledge sharing: The role of organizational rewards systems," Journal of Leadership and Organization Studies, vol. 9, no. 1, pp. 64-76, 2002.

[25] P. Senge, "Sharing Knowledge: You can't own knowledge, so why not share it?" Executive Excellence, vol. 15, pp. 11-12, 1998.

[26] D. Leonard and S. Sensiper, "The role of tacit knowledge in group innovation," California management review, vol. 40, no. 3, 1998.

[27] J. Biggam, "Defining knowledge: An epistemological foundation for knowledge management," in 2001 Proc. the 34th Annual Hawaii International Conference on System Sciences, January 2001, p. 7.

[28] N. Hara, "Information technology support for communities of practice: How public defenders learn about winning and losing in court," Journal of the American Society for Information Science and Technology, vol. 58, no. 1, pp. 76-87, 2007.

[29] C. S. Chen, S. F. Chang, and C. H. Liu, "Understanding knowledge-sharing motivation, incentive mechanisms, and satisfaction in virtual communities," Social Behavior and Personality: an international journal, vol. 40, no. 4, pp. 639-647, 2012.

[30] M. Boylan, "Ecologies of participation in school classrooms," Teaching and Teacher Education, vol. 26, no. 1, pp. 61-70, 2010.

[31] R. E. Brown, "The process of community-building in distance learning classes," Journal of asynchronous learning networks, vol. 5, no. 2, pp. 18-35, 2001.

[32] G. C. Homans, "Social behavior as exchange," American journal of sociology, pp. 597-606, 1958.
[33] P. M. Blau, Exchange and power in social life, Transaction Publishers, 1964.

[34] L. F. Liao, "Knowledge-sharing in R\&D departments: a social power and social exchange theory perspective," The International Journal of Human Resource Management, vol. 19, no. 10, pp. 1881-1895, 2008.

[35] E. L. Deci and R. M. Ryan, "The empirical exploration of intrinsic motivational processes," Advances in experimental social psychology, vol. 13 , no. 2, pp. 39-80, 1980.

[36] A. Portes and J. Sensenbrenner, "Embeddedness and immigration Notes on the social determinants of economic action," The new institutionalism in sociology, pp. 127-49, 1998.

[37] C. R. Leana and H. J. V. Buren, "Organizational social capital and employment practices," Academy of management review, vol. 24, no. 3, pp. 538-555, 1999

[38] J. Nahapiet and S. Ghoshal, "Social capital, intellectual capital, and the organizational advantage," Academy of management review, vol. 23 , no. 2, pp. 242-266, 1998

[39] A. Bandura, "The explanatory and predictive scope of self-efficacy theory," Journal of Social and Clinical Psychology, vol. 4, no. 3, pp 359-373, 1986

[40] A. Bandura, Self-efficacy: The exercise of control, Macmillan, 1997.

[41] M. Fishbein and I. Ajzen, Belief, attitude, intention and behavior: An introduction to theory and research, 1975.

[42] I. Ajzen and M. Fishbein, Understanding attitudes and predicting social behaviour, 1980.

[43] F. D. Davis, R. P. Bagozzi, and P. R. Warshaw, "User acceptance of computer technology: a comparison of two theoretical models," Management science, vol. 35, no. 8, pp. 982-1003, 1989.

[44] A. Kankanhalli, B. C. Tan, and K. K. Wei, "Contributing knowledge to electronic knowledge repositories: an empirical investigation," Mis Quarterly, pp. 113-143, 2005.

[45] G. C. Moore and I. Benbasat, "Development of an instrument to measure the perceptions of adopting an information technology innovation," Information systems research, vol. 2, no. 3, pp. 192-222, 1991.

[46] E. M. Rogers, Diffusion of innovations, New York, 1995

[47] S. W. Hung and M. J. Cheng, "Are you ready for knowledge sharing? An empirical study of virtual communities," Computers \& Education vol. 62, pp. 8-17, 2013.

[48] M. H. Hsu, T. L. Ju, C. H. Yen, and C. M. Chang, "Knowledge sharing behavior in virtual communities: The relationship between trust, self-efficacy, and outcome expectations," International Journal of Human-Computer Studies, vol. 65, no. 2, pp. 153-169, 2007.

[49] M. L. Young, and F. C. Tseng, "Interplay between physical and virtual settings for online interpersonal trust formation in knowledge-sharing practice," CyberPsychology \& Behavior, vol. 11, no. 1, pp. 55-64, 2008.

[50] O. P. Kauppila, R. Rajala, and A. Jyrämä, "Knowledge sharing through virtual teams across borders and boundaries," Management Learning, vol. 42, no.4, pp. 395-418, 2011.

[51] A. J. Elliot, Handbook of approach and avoidance motivation, Taylor \& Francis, 2008.

[52] W. Tsai and S. Ghoshal, "Social capital and value creation: The role of intrafirm networks," Academy of management Journal, vol. 41, no. 4, pp. 464-476, 1998

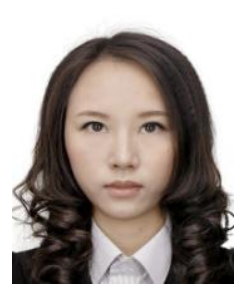

Yongsi Chan is currently a M.Sc student majoring in information technology in education, at the Faculty of Education, The University of Hong Kong. Her research interest includes information technology in education, impact measurement of knowledge management and organizational impact of information technology.

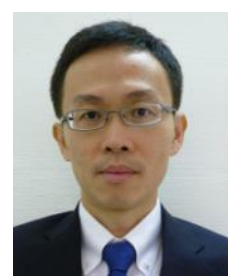

Khe Foon Hew is an associate professor of information and technology studies at the Faculty of Education, The University of Hong Kong. His research primarily focuses on computer-supported social interaction, e-learning design \& technology. 